\title{
On Conservation Science's Topical Issue to Help Art Being Understood in a Humanistic Way
}

\author{
Hiltrud Schinzel \\ International Institute for Advanced Studies in Systems Research and Cybernetics (IIAS) \\ European Division, Muelheimerstr. 7, D-40239 Duesseldorf \\ Germany \\ hiltrud.schinzel@t-online.de
}

ABSTRACT: The paper considers the interconnections of conservation and education. The accent is on the possibilities of increasing the role of art (in particular, of its conservation and restoration) in supporting and developing cognitiveemotional sphere of the students (as concerns upbringing of feelings and deepening empathic perceptions), in bridging a gap between feeling and thinking.

Keywords: Digital Arts, Digital Education, Cognition

Received: 13 September 2018, Revised 2 December 2018, Accepted 18 December 2018

DOI: $10.6025 / \mathrm{jdp} / 2019 / 9 / 2 / 46-50$

(C) 2019 DLINE. All Rights Reserved

\section{Introduction}

Eric Kandel describes our relationship to art as follows:

'Our response to art stems from an irrepressible urge to recreate in our own brains the creative process-cognitive, emotional, and empathic - through which the artist produced the work... Art is an inherently pleasurable and instructive attempt by the artist and the beholder to communicate and share with each other the creative process that characterizes every human brain' [1, p. 393].

Those involved in art are primarily concerned with communication, not objectivity, as in the sciences. Werner K. Heisenberg once said: 'The kind of reality which we are able to talk about is never reality itself'. Similarly, the reality that we can see and describe is never reality itself. Yet we have the opportunity to learn from other experiences by the arts. By art works in a metaphorical way we have the ability to experience visual, literary, and oral stories aesthetically and to integrate their content into our individual lives. A particular point of fascination here is that we actually learn more about ourselves through works of art, a fact that is of great importance to education.

This paper considers the interconnections of conservation and education. The accent is on the possibilities of increasing the role of art (in particular, aided by conservation and restoration) in supporting and developing cognitive-emotional sphere of the 
students (as concerns upbringing of feelings and deepening empathic perceptions), in bridging a gap between feeling and thinking.

\section{Relatedness of Conservation and Education}

My profession conservation has always been one of caring for artefacts in many ways. Yet, it could be supplemented by doing this more consciously than up till now. By being nonverbal it's care might influence the education and nurturing of human behaviour in a subtle visual way. Educational researchers pointed out that social behaviour has been disrupted by the abuse of new technologies, in a process that now starts as early as childhood [2 - 5]. Each epoch is committed to a different set of conditions; the more those conditions are bound to evolutionary mechanisms such as technology, the more removed they become from natural states. Nevertheless, art always renders human feelings visible, which are in turn understandable in any epoch. Conservation has always been applied to help such understanding by mediating between art and the contemporary recipient.

This might be demonstrated by the subject suffering in Christian religious art. Although suffering of Christ and/or saints is readily grasped by anyone, means of expression remain specific throughout art's history even in the same local circumstance. Nevertheless, regarding artwork on such theme, the chains of association lead each viewer to remember humiliating experiences in his or her own life, regardless of the period and cultural environment in which he or she lives. The empathy felt by identifying with the image opens up pathways to understanding and compassion. These mechanisms were discovered by behavioural science, and there is neuronal evidence of their activity in the human brain. I am of the firm opinion that in a world which has become emotionally dumbstruck through visual sensory overload, a particularly important task for conservation is to enable and assist such emotional experiences in the viewer.

There are scores of new technical tools that provide us with historical data. But when it comes to providing historical feeling, there are virtually none. That emotional experience or empathy is a general concern for humankind today can be attested in a quotation from artist Andy Goldsworthy. Regarding the durability of his works, he states in an interview [6]:

'The most tangible, permanent thing that I will leave is the story of something that was made in that (referring to a local) place and that people saw it being made - knew that the materials came from the site.... And then the work made in front of everyone's eyes, and the anxieties, the fears, and worries along the path of the piece. That's the result of the piece.... And the photographs and the talking now are all part of that story. I think that's a legitimate form of sculpture. Even when the object's gone'.

Goldsworthy here makes deliberate reference to the emotional states that accompany the production of an artwork. The field of conservation-restoration is currently undergoing considerable technical changes triggered by the 'digital revolution' which is affecting all walks of life. A particular case in point here is the phenomenon of 'iconic works' corresponding to the topical hero worship of so called role-models. In conservation this led to a division between the person who researches data and the practitioner whose work is hands-on. We have all experienced the advantages and disadvantages of digital support, but two things bother me about its application in conservation and in life in general:

1. The lack of 'tactile contact' with the object that is crucial for our line of work.

2. The ongoing technical difficulty of converting data into knowledge - an unresolved problem in systems research that only increases with the growing amount of data.

In view of current problems faced in education, much of the research currently being conducted in a variety of subjects is increasingly turning to the role of feelings in learning. Besides behavioural science, empathy research appears to have an important role to play in the context of conservation. Empathy is generally understood to mean 'the ability to understand and share the feelings of another' (Oxford). It evolved in the oldest parts of the brain. Empathy and 'visual thinking' both originated before language and were important for human survival. 'Empathic perceptions have an immediate and direct impact and are not influenced by social expectations. This makes them true to reality', writes psychoanalyst Arno Gruen [7]. Looking at art teaches us empathy and so, by extension, conservation has the potential to teach us how to fine-tune that empathy.

It is no stretch of the imagination to say that earlier artist restorers demonstrated much, indeed from today's objectivity-

Journal of Data Processing Volume 9 Number 2 June 2019 
searching perspective, even too much feeling for the works of their predecessors and therefore unconsciously enriched them with associations specific to their day. The emotional spectrum behind their motivations in doing so may have been similar to the one described by Goldsworthy but reflected quite different historical and social circumstances. One cannot expect today's science-based conservator or restorer to show an awareness of such emotional states. Or if one does, they at least cannot be given the same emphasis in teaching as the body of technical information known to constitute fact today.

As a result therefore, far too little is known of the influence of emotions and emotional responses on the conservation and restoration of works of art. However, neuro-scientific findings provide evidence that the following things are just as important as facts: sensitivity for the object's material, emotional empathy for the circumstances which accompany the creation of the artwork and for its later social history.

Only if awareness exists of the emotional factors that go into art production and conservation, are the treatments possible that aim for a holistic perception in today's viewer. And by 'holistic' I mean an informed balance between fact and feeling. As Arno Gruen states, unfortunately 'the separation of feeling and thinking [is] a process that has long become characteristic of our social consciousness' [7]. As far as conservation science is concerned, it seems to me that our profession does not sufficiently recognize the fact that technique and material instil and convey feelings in the viewer. As a result, the possibilities that this fact holds regarding art education and art appreciation are currently insufficiently exploited, if at all.

\section{The Possibilities of Material and Aesthetic Phenomena: The Results of an Experiment}

There are special emotional properties inherent for instance in wood that support certain metaphorical characteristics which are well recognized by conservation practitioners. As an example, let's consider the observations accumulated during an experiment that took place in May of 2015. This experiment was a part of a private initiative for integrating refugees into German rural environment where residential homes are located.

The introduction to this experiment reads as follows:

'Integration does not only concern those who came. Those who house have to deal with this state too. Different cultures have different pasts and different ways to meet. Therefore it is difficult to understand each other. In an environment shaped by civilization it is not as easy to find common ground as it is in nature and art.

Writer Henning Mankell lets a fugitive girl say: "You did not hear me, you only heard your own voice. You did not see me, you only saw a person that your words created" [8]. Let us compare what we can see in some images in order to learn from each other'.

Then the refugees were acquainted with a series of photographs provided by a power point (PP) presentation. The photographs showed the sad consequences of a storm that devastated a park.

Already while showing the PP, some discussion arose from images. One example was the question: what means color for the participants personally. Answers varied: colors meant for instance for one life, for the other freedom, the third light, for another one energy. Differences of cultural meanings of some colors were mentioned. This gave lively proof to the fact that cultural habits can divide and cause conflict. One consequence was accepted: characteristics of cultures have to be mutually understood and respected for living together in harmony.

There were - alas - only male refugees present, mostly between 18 and 30 years old. The reason is that women generally are not fit for the strains of flight. Most of the young men could not discuss in German, and although a translator was present, all preferred to talk by images after the presentation had ended. The tools I had provided for this aim were papers of various size, pencils, pastels and modern writing tools. It was very interesting, that no one chose modern objects like felt pen or marker. Most wanted were pastels followed by colored pencil. Most of the visual narrators took rather large papers, which they filled without any anxiety and/or awe.

Lines were drawn slowly and accurately with sure hand. During drawing, intense concentration was interrupted from time to time by looking at the neighbour's doing and having fun. Few of the German people took part of this practical expression, yet some worked very nicely together.

$48 \quad$ Journal of Data Processing Volume 9 Number 2 June 2019


It was interesting, that whereas the refugees were all able to recognize their own fate in the metaphor storm and tree, some German participants evidently did not understand the metaphoric visual language. This came out in personal talk after the presentation. For instance, one insurance person associated an uprooted trunk in the materialistic way of his own world: lacking is original function such wood was regarded as being of no use and on top of it all causing serious trouble to get rid of. This reaction clearly showed that in our neoliberal Christian society there is no feeling for not even comprehension of care for the seemingly useless fellow being. Evidently, such human beings are regarded as material de trop in short as object from an economical point of view and on top of this lamented to cause efforts and costs. Although some minutes before we had discussed the arbitrariness of fate by showing that a storm can hit anybody regardless his/her home and culture, fate's arbitrariness being unjust did not reach the consciousness of this representative of insurance business, a profession dealing with their clients fears!

Of course, for a conservator such attitude is a total error. We know that nature and cultural goods have to be protected as their function never ends, regardless whether it is the original one or not. They are of utmost importance for any cultural consciousness incorporating humanism. Nevertheless we have to take into account very seriously what the described- alas widespreadattitude in neoliberal economies might mean for the future of the world's heritage and our living perspectives.

The most moving drawing for me was a pencil drawing of a young Syrian describing his longing for home. As Churchill, who was a painter too, once said: It takes a lot of courage to draw a true narrative. Astonishing too was the care with which the refugees worked, how delicate their drawings were and that the wishes they contained were so elementary, all related to basic human needs: A peaceful natural environment was mainly expressed by water and flowers, a female companion was another understandable wish. Form- and color-structuring respectively, calligraphic beauty combined with verbal essence was equally impressive.

To see these young men's natural feeling for and attachment to beauty was as convincing as consoling for a conservator living in a more and more technically dominated environment conquered by engineered illusions of aggressive competition. In my view, their visualized wishes were directly opposed to the optic disturbances and visually brutal and childish advertising of existential uncalled for products that surround everyday life, disturb mentality and ruin environment more and more.

Many aggressive and deceptive illusions are openly visible in many so to speak peaceful environments like shopping. This discrepancy between images of topical warlike advertisement and the art of persons really having suffered from war is strikingly evident. Outcome of this comparison is an intense feeling that today's superficial, kitschy, visually cruel, cultural environment needs the influence of the basic human feelings the refugee's drawings expressed - just as much as refugees need our material help. One might rightly wonder who might help whom to a higher degree from a humanely point of view. If it could be made understood that immigrants as well as welcoming locals can both teach and learn from each other at the same time, a win-win situation could develop.

\section{Conclusion}

Our basic conflicts today as always derive from (aiming at and wanting to keep) richness causing poorness. In such processes what we now call human rights always were neglected. Conflict is the unavoidable outcome. Source of the topical image of such conflict is the sad heritage of colonization supported by the advantages advanced technology always could provide. The emigration from many nations, we encounter today, originated from this background. The reasons politics offer for conflicts are often an escape to admit that a general problem exists. Arguing is usually supporting short-term decision making.

Therefore it is no wonder that the ruling reality for both refugees and their welcoming people today is: Everything has to function for a market. Misery is treated as salable product mainly by brutal images. Highly emotional protests that reach us by war-artist's works are a new collecting aim in Dubai and London. It will need much education which could be given by refugees not interested in revenge to teach us well-off a better view on life than the one-sided tunnel vision of unjustifiable markets. Only with this understanding a general conservation of acts of humanity is possible. To conserve humane aspects made transparent by art for the author is the most important and topical challenge of conservation profession.

\section{References}

[1] Kandel, E. (2012). The Age of Insight. New York. 
[2] Fomichov, V. A., Fomichova, O. S. (2000). The Social Responsibility of Computer Science Specialists for the Creative Potential of the Young Generation. International Journal of Artificial Intelligence in Education 11. p. 208-219. 2000.

[3] Fomichova, O. S., Fomichov, V. A. (2000). Computers and the Thought-Producing Self of the Young Child. The British Journal of Educational Technology 31. p. 213-220. 2000.

[4] Fomichov, V., Fomichova, O. (2006). Cognitonics as a New Science and Its Significance for Informatics and Information Society. Special Issue on Developing Creativity and Broad Mental Outlook in the Information Society (Guest Editor Vladimir Fomichov), Informatica. An International Journal of Computing and Informatics (Slovenia) 30. p. 387-398.

[5] Spitzer, M. (2012). Digitale Demenz. Droemer VI eBook. Munich. 2012.

[6] Goldsworthy, A. Audio Portion of Interview Video with Andy Goldsworthy, Storm King Art Center, Mountainville, New York, interview by Mildred Constantine and Paul Bochner, Getty Conversation Institute, Los Angeles, 28 October 1997, typescript, 11.

[7] Gruen, A. (2013). Dem Leben Entfremdet: Warum wir wieder lernen müssen zu empfinden. Stuttgart 2013 (quotes on pages 12 and 61 are translated by the author).

[8] Mankell, H. (2001). Tea-Bag. First published in Sweden. 2001. 